\title{
Low-Cost Pathway to Ultra Efficient City Car: Series Hydraulic Hybrid System with Optimized Supervisory Control
}

\author{
Rajit Johri and Zoran Filipi \\ University of Michigan, Ann Arbor
}

\begin{abstract}
A series hydraulic hybrid concept (SHHV) has been explored as a potential pathway to an ultra-efficient city vehicle. Intended markets would be congested metropolitan areas, particularly in developing countries. The target fuel economy was $\sim 100 \mathrm{mpg}$ or $2.4 \mathrm{l} / 100 \mathrm{~km}$ in city driving. Such an ambitious target requires multiple measures, i.e. low mass, favorable aerodynamics and ultra-efficient powertrain. The series hydraulic hybrid powertrain has been designed and analyzed for the selected light and aerodynamic platform with the expectation that (i) series configuration will maximize opportunities for regeneration and optimization of engine operation, (ii) inherent high power density of hydraulic propulsion and storage components will yield small, lowcost components, and (iii) high efficiency and high power limits for accumulator charging/discharging will enable very effective regeneration. The simulation study focused on the SHHV supervisory control development, to address the challenge of the low storage capacity of the accumulator. Two approaches were pursued, i.e. the thermostatic SOC control, and Stochastic Dynamic Programming for horizon optimization. The stochastic dynamic programming was setup using a set of naturalistic driving schedules, recorded in normal traffic. The analysis included additional degree of freedom, as the engine power demand was split into two variables, namely engine torque and speed. The results represent a significant departure from the conventional wisdom of operating the engine near its "sweet spot" and indicate what is preferred from the system stand-point. Predicted fuel economy over the EPA city schedule is $~ 93 \mathrm{mpg}$ with engine idling, and $\sim 110 \mathrm{mpg}$ with engine shutdowns.
\end{abstract}

\section{INTRODUCTION}

The energy security and climate change challenges provide strong impetus for pursuing ultra-efficient vehicle concepts. The fuel economy of passenger vehicles shows very strong dependency on vehicle mass and aerodynamic drag, but hybridization enables departures from the trend and significant leaps in fuel economy improvements. The mechanisms for improvements include possibility for engine downsizing, optimization of engine operation, regeneration and engine shut-downs when the vehicle is stopped. The relative contribution of each depends on the architecture, e.g. parallel, powersplit or series, selection of component and the type of application. In the context of a small passenger vehicle, the series configuration holds a promise of maximizing benefits through flexibility in controlling the engine and effective regeneration, since by default the traction motor will be sized generously. However, larger sizes of components in the hybrid driveline create a cost challenge. Hence, this study explores the potential of the hydraulic hybrid propulsion system, with the expectation that inherently high power density of hydraulic propulsion and storage components will yield compact, low-cost components [1]. While state-of-the art hydraulic pump/motor technology for mobile applications includes very advanced designs, manufacturing is mature and can easily be setup in any region of the world.

The series hydraulic hybrid driveline comprises propulsion pump/motors coupled to front and rear differentials and a hydro-pneumatic accumulator for energy storage. Coupling another hydraulic pump to the engine creates a power generation sub-system. The particular advantages of hydraulics relevant for series 
architectures are the high-efficiency of the hydraulic pump/motor and high power limits for accumulator charging/discharging. They both contribute to very effective regeneration, and to some extent mitigate the effect of multiplying efficiencies in the propulsion chain. The comparatively low energy density of the hydraulic accumulator creates a special challenge and requires novel approaches to development of supervisory control.

The features of the parallel and series hydraulic hybrid vehicle architectures have been investigated before, particularly in the context of heavier vehicles [2, 3, 4] and the optimization of the design and control strategies led to impressive fuel economy improvements. However, the application of a series hydraulic hybrid concept to a very small car has only recently caught attention $[5,6,7]$. It is our goal to utilize some of the advanced methodologies previously demonstrated in studies of heavy vehicles to maximize the fuel economy of the SHHV system for a small car. The particular focus is on the supervisory control development. This is of critical importance for SHHV analysis since the low storage capacity of the hydraulic accumulator creates a special challenge for controller development, very different than in the case of electric system. The low-cost objective requires keeping the component sizes as small as possible, therefore emphasizing the impact of power management.

The aim of this paper is to demonstrate a hydraulic hybrid system for an ultra small city car. The target fuel economy is $\sim 100 \mathrm{mpg}$ or $2.4 \mathrm{l} / 100 \mathrm{~km}$ in city driving. Hence, the baseline for the study is a first-generation Honda Insight IMA Hybrid Electric Vehicle, as its aluminum structure and aerodynamic body represent the state-of-the-art for a given category. The series hydraulic hybrid powertrain is designed and analyzed for the selected platform using a simulation developed in SIMULINK.

Two approaches for supervisory control development are pursued, i.e. the Thermostatic State-Of-Charge (SOC) control and Stochastic Dynamic Programming (SDP) for horizon optimization of the supervisory policy. In the case of Thermostatic control, we challenge the conventional wisdom of operating the engine at the "sweet spot" and search for optimal $\mathrm{SOC}_{\text {threshold }}$ and power threshold during charging. In the SDP investigation, we take the notion that system effects dominate over the componentcentric approach a step further. Namely, the technique includes selection of engine torque and speed, rather than just the power level, thus allowing departures from the best BSFC line if it benefits the overall powertrain efficiency.

The paper is organized in three major sections. First, we explain the modeling of the baseline Honda Insight HEV. This includes in-depth review of its control strategies and electrical system operation based on data available in literature [8]. The second section proposes the new series hydraulic hybrid vehicle configuration. Modeling of hydraulic components and integration of the complete SHHV system is included. Detailed description of the two control approaches follows, i.e. the Thermostatic SOC management and SDP horizon-optimization. The stochastic dynamic programming is setup using a set of naturalistic driving schedules, recorded in normal traffic. Results of both supervisory control methodologies are discussed to uncover the mechanism of fuel economy improvements. Finally, we discuss the findings and the compare the fuel economy results of the SHHV vehicle to the baseline IMA HEV. The paper ends with conclusions.

\section{BASELINE ISA HYBRID CONFIGURATION}

A low cost city car with very high fuel economy will require a very light body with superb aerodynamics. Honda Insight (first generation) is used as a starting point for a light vehicle platform because it represents the state-of-the art in addressing both the light weight and aerodynamic drag. Honda Insight is a pretransmission parallel electric hybrid, as shown on the schematic in Figure 1. The motor augments the engine torque under high load and hence is also called Integrated Motor Assist (IMA). Honda Insight does not have a conventional alternator and uses the IMA for other electrical needs.

Honda Insight in North America has a 5 speed manual transmission. Manual transmission offers higher efficiencies at steady state speeds but forces the driver to choose the optimal gearing to keep engine operation near optimal. High fuel economy of Honda Insight is attributed to its small engine and attention to every source of vehicle losses. The impact of hybridization, including the ability to regenerate will be highlighted later in the paper through comparisons with the SHHV.
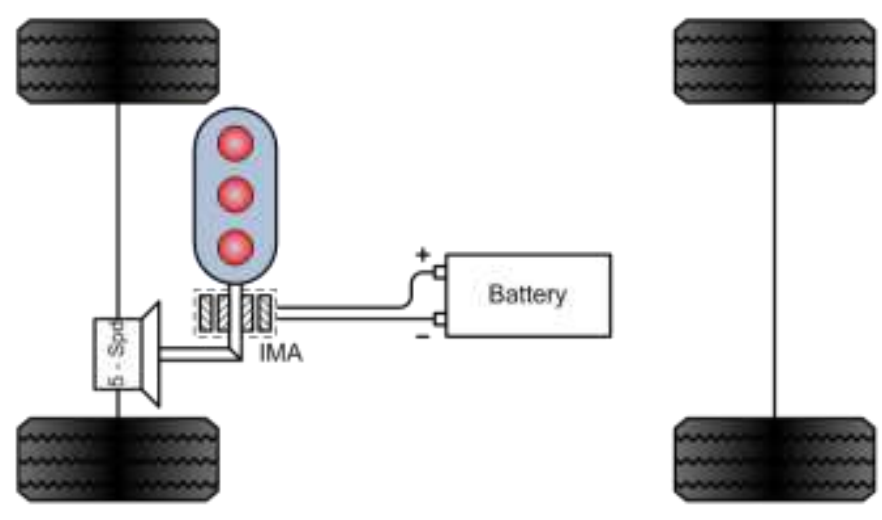

Figure 1 : Hybrid electric vehicle architecture with Integrated Motor Alternator

Honda Insight model is used as a baseline vehicle for performance and fuel consumption comparison. The model will be validated using the published results on Honda Insight, [8]. Table 1 gives the specifications of the baseline Honda Insight vehicle. 
Table 1 : Honda Insight Specifications

\begin{tabular}{lll}
\hline Engine & Description & 1L VTEC \\
& Max. Power & 49kW @ 6000 RPM \\
& Max. Torque & 90 Nm @ 4600 RPM \\
\hline \multirow{2}{*}{ Motor } & Design & Brushless Permanent \\
& Max Power & Magnet DC \\
& Design & Nickel Metal Hydride \\
Battery & spiral wound cells \\
& Capacity & $0.9 \mathrm{kWhr}$ \\
\hline Vehicle & Type & Sedan \\
& Weight & $962 \mathrm{~kg}$ \\
& Coeff. of Drag & 0.25 \\
& Frontal Area & $1.9 \mathrm{~m}$ \\
& Tire Radius & $0.275 \mathrm{~m}$ \\
& Final Drive & 3.21 \\
& Ratio & $5 \mathrm{speed}$ Manual \\
& Design & $3.46,1.75,1.1,0.86,0.71$ \\
\hline Transmission
\end{tabular}

\section{ENGINE}

The engine model takes driver command and external load torque as input and calculates the engine speed and fuel consumption. The engine model is based on look-up table which outputs engine torque as a function of fuel input and engine speed. The look-up table is obtained from ADVISOR, [9] and is based on testing done by NREL and ANL. Figure 2 give the SIMULINK implementation of engine.

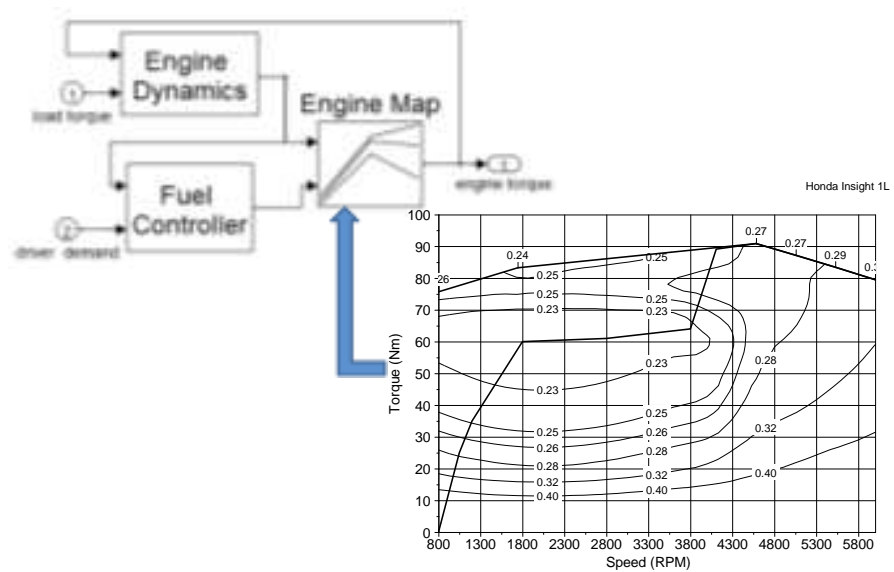

Figure 2 : Engine model in SIMULINK

\section{TRANSMISSION AND VEHICLE}

Honda Insight has a 5 speed manual transmission. The gearbox is modeled as a finite state machine with different gear being the different states of the system. A blending function is added to simulate inertia and torque phase during gear shift. Blending function provides a fast and fairly accurate way of incorporating these phases. The gear shifting logic is based on vehicle speed, according to test procedures laid out by the EPA.
The clutch is modeled based on the normal pressure theory. The maximum torque transmitted is proportional to the normal force applied. There are two distinct modes of operation in clutch: 1) slipping - the two plates have differing angular velocities and, 2) lockup - the two plates rotate together. Controller logic engages and disengages the clutch to reduce the torque discontinuity during clutch engagement/disengagement.

$$
\begin{gathered}
T_{f \max k}=\frac{2}{3} R F_{n} \mu_{k} \\
T_{d}=\operatorname{sgn}\left(\omega_{e}-\omega_{v}\right) T_{f \max k}
\end{gathered}
$$

where $\omega_{e}$ and $\omega_{v}$ are the speeds across clutch, $T_{\text {fmaxk }}$ is the clutch max torque capacity, $R$ is clutch radius, $F_{n}$ is the normal force on clutch and $\mu_{k}$ is the friction coefficient.

The vehicle is modeled as point mass system and pitch plane dynamics are ignored. This is deemed sufficient for the fuel economy studies. The resistive forces were modeled as rolling and drag resistance. The vehicle also contains a brake model, which acts as a coulombic friction device.

\section{ELECTRICAL SYSTEM}

Electrical sub-systems is composed of a Brushless Permanent Magnet DC motor, and a Nickel Metal Hydride battery. Their characteristics are described in the following.

Battery - is modeled as an equivalent circuit comprising a perfect open circuit voltage source, $V_{O C}$ in series with an effective internal resistance, $R_{\text {int }}$ based on ADVISOR data [9]. $\quad V_{O C}$ and $R_{\text {int }}$ are computed as piecewise linear functions of SOC. There are two such functions for computing $R_{\text {int }}$, one for discharge power and another for charge power. Equivalent circuit current is solved from the $\mathrm{V}_{\mathrm{OC}}, \mathrm{R}_{\mathrm{int}}$ and maximum power battery can deliver. The battery current is then used to update the effective SOC of the battery. The thermal model of the battery calculates the module temperature, which is fed back to be used in determining the performance parameters.

Motor - is modeled as 2D lookup table [9] with efficiency of the motor as function of motor torque and motor speed. The motor dynamics are approximated by a firstorder lag. However, due to the battery power and motor torque limit, the final motor dynamics assume the following form

$$
T_{m}=\left\{\begin{array}{l}
\min \left(T_{m_{-} \text {req }}, T_{m_{-} \max }, T_{m_{-} \text {bat }}\right) \frac{\lambda_{m}}{s+\lambda_{m}}, \text { motor } \\
\max \left(T_{m_{-} \text {req }}, T_{m_{-} \max }, T_{m_{-} \text {bat }}\right) \frac{\lambda_{m}}{s+\lambda_{m}}, \text { generator }
\end{array}\right.
$$


where $T_{m}$ is the motor torque, $T_{m_{-} \text {req }}$ is the requested motor torque, $\mathrm{T}_{\mathrm{m} \_ \text {max }}$ is the maximum torque motor can generate at given condition and $\mathrm{T}_{\mathrm{m} \_ \text {bat }}$ is the max motor torque due to battery limitations. $\lambda_{\mathrm{m}}$ is the inverse of the motor time constant.

\section{SUPERVISORY CONTROLLER}

A rule based control strategy is developed for Insight based on data from testing done by Argonne National Laboratory (ANL) and National Renewable Energy Laboratory (NREL) [8]. Rule-based controller design relies on engineering intuition and is typically componentcentric. Our primarily goal here is to establish a representative baseline for comparison with the HHV, hence we relied on the published data to achieve behavior observed during testing of the production vehicle [8].

The vehicle power demands are managed through a supervisory controller. The strategy is influenced by the fact that the vehicle with IMA represents a very mild hybrid. During acceleration, the engine is the prime mover and most of the propulsion torque comes from the engine. The motor supplements additional torque to keep the engine operation near the optimal except during 1st gear driving. This is done to keep motor from operating at low efficiency regions. The motor also acts as alternator for the vehicle and provides the energy for accessories. During braking event, the controller commands motor to act as an alternator for recharging the battery. Friction brakes are applied when the power demand exceeds either motor or battery capabilities, or if vehicle speed is below certain speed.

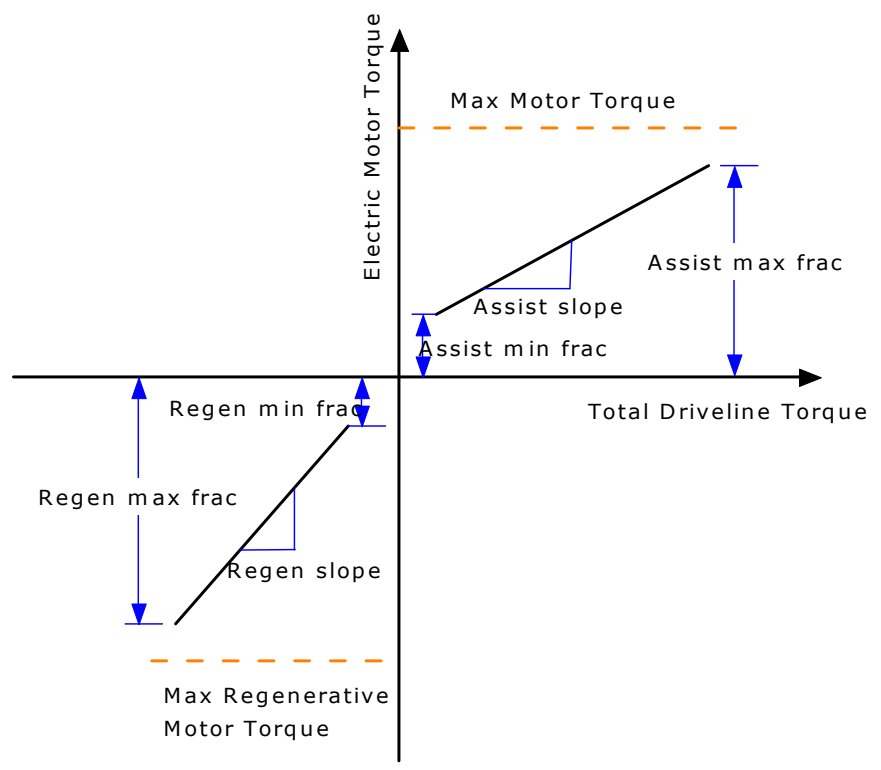

Figure 3 : Honda Insight strategy for controlling motor torque based on total driveline torque [9].

Motor demand during acceleration and deceleration are based on ratio of total driveline torque required by the vehicle. The SOC of battery is maintained near 0.68 to increase battery life. Based on driver commands, the controller calculates the power demand by the vehicle. Positive power demand is fed to the driving logic which calculates the torque split between engine and motor. Motor torque is calculated based on gear number and total driveline torque required using the logic shown in Figure 3 [9].

Based on the torque and rate of acceleration, the electric motor assists the IC Engine, producing around $10 \mathrm{Nm}$ of torque.

- There is no electric assist in the first gear.

- In case SOC drops below a threshold value, engine provides all the torque.

- If the power demand crosses a predefined value with SOC below threshold, the motor is operated as generator to trickle charge the battery until desired SOC is reached.

In case of negative power demand, the braking logic calculates the ratio between motor braking and friction braking.

- During regeneration, the electric motor provides a portion of the negative torque available to the driveline.

- At low vehicle speeds, typically below $10 \mathrm{mph}$, the braking is primarily by the friction brakes as the amount of kinetic energy diminishes.

For the Honda Insight, the engine remains on in most cases. The following criteria define when the engine is allowed to shut off. The engine in the Insight will only shut down if all of the following conditions are satisfied

- Engine is warm.

- Battery SOC is greater than the low SOC set point.

- Vehicle is decelerating or stopped; no gear shifting

\section{RESULTS - BASELINE HYBRID ELECTRIC VEHICLE (IMA)}

The Honda Insight SIMULINK model was simulated over different EPA cycles. Figure 4 to Figure 6 show the engine and motor operation during FUDS cycle. The engine is operated at low speeds to allow higher BSFC region operation. However, the dominant regimes are still characterized by low load, as a result of the relatively mild power requirements during FUDS and constraints imposed by the mechanical driveline. The predicted traces of motor torque vs. driveline torque indicate success in implementing the blending strategy seen in the production IMA vehicle (see Figure 5). The motor runs in a favorable speed range, but at relatively modest loads (see Figure 6). The overall low driveline power requirements, as well as management of a tradeoff between drivability and efficiency, prevents the motor from running at higher loads and closer to maximum efficiency. The electrical machine is used very aggressively during regeneration. 


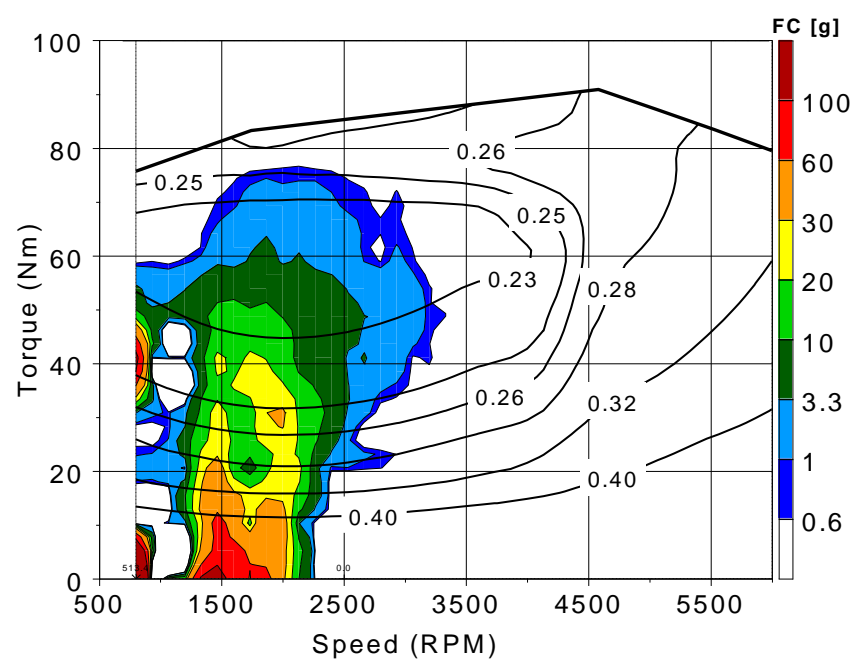

Figure 4 : Engine visitation points on the BSFC map, with color scale indicating the relative amount of fuel consumed in a given zone during FUDS for baseline IMA Hybrid Electric Vehicle

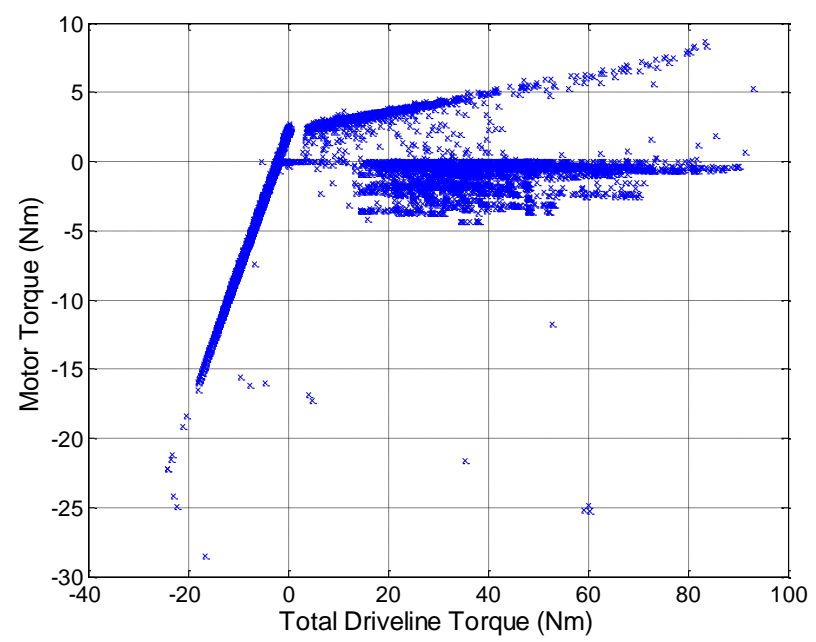

Figure 5 : Predicted IMA torque as a function of total driveline demand, illustrating the IMA control strategy.

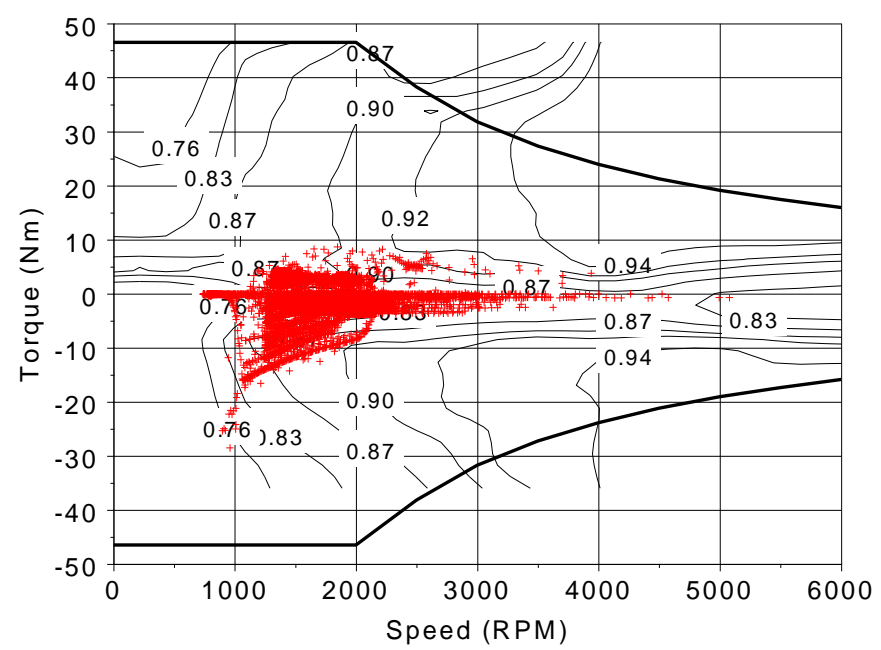

Figure 6 : Motor operation visitation points on the efficiency map during city driving (EPA FUD).
Figure 7 shows engine power, gear number and motor torque histories during part of the FUDS driving schedule. Figure $7 \mathrm{~b}$ indicates that engine operates relatively close to the load-following mode due to a mild assist from IMA (see Figure 7d). The motor provides zero torque at launch (in $1^{\text {st }}$ gear), as intended by the controller designers. Figure $7 \mathrm{~d}$ also illustrates capturing of the braking energy around the 180-second mark, and during deceleration down to stand still at the end of this vehicle speed profile.

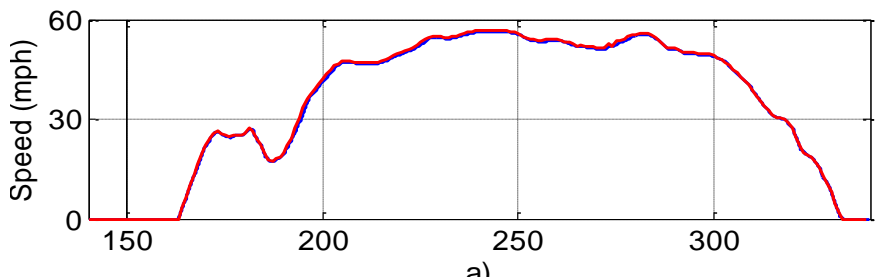

a)

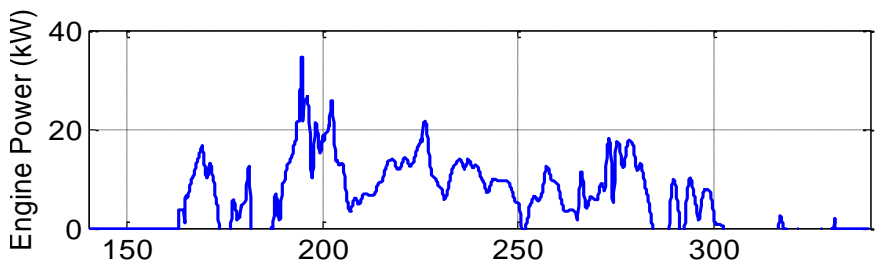

b)
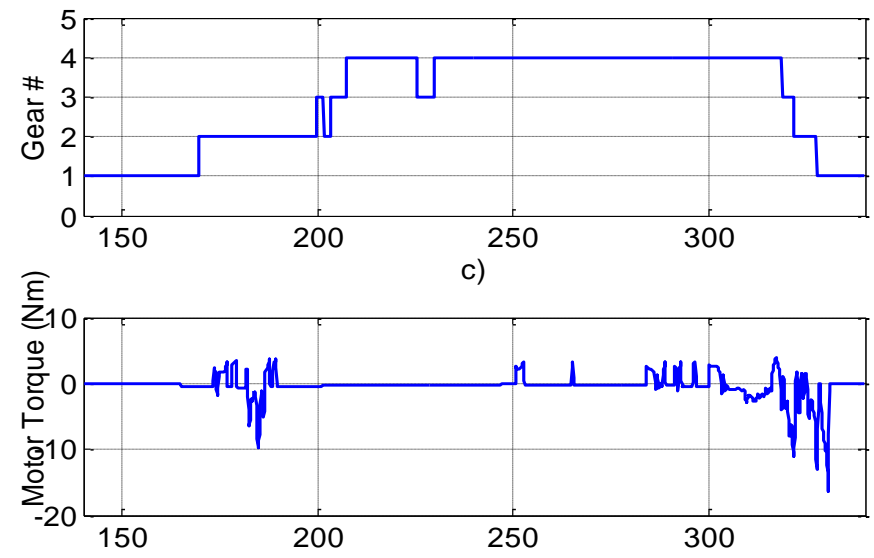

d)

Time(sec)

Figure 7 : Predicted interactions in the IMA HEV propulsion system: a) Vehicle Speed, b) Engine Power, c) Gear \# and d) Motor Torque, for a section of FUDS cycle from $140 \mathrm{sec}$ to $340 \mathrm{sec}$

From Table 2, it can be seen that the model over predicts the fuel economy over the published EPA values. This is mostly due to the fact that the model ignores modifications of engine fueling strategies during and after cold start. However, the same assumptions will be used in our subsequent study of the hydraulic hybrid powertrain, hence using the simulated values for IMA HEV fuel economy will ensure the fair comparison. 
Table 2 : IMA HEV (Honda Insight) Fuel Economy

\section{Simulated EPA}

Urban Cycle (FUDS)

61.6

60

Highway Cycle (HWFET)

73.38

66

\section{SERIES HYDRAULIC HYBRID}

A series hydraulic hybrid, Figure 8 is modeled in SIMULINK, using the in-house developed component models and the integration approach described by Kim et al. in [4]. A series system allows full flexibility in engine operation, as there is no mechanical connection between the engine and the wheels. Hydraulic components offer very high power density and efficiency and hence are highly suitable for vehicular applications, in particular for a series system where full amount of power needs to be provided by the alternative propulsion component.

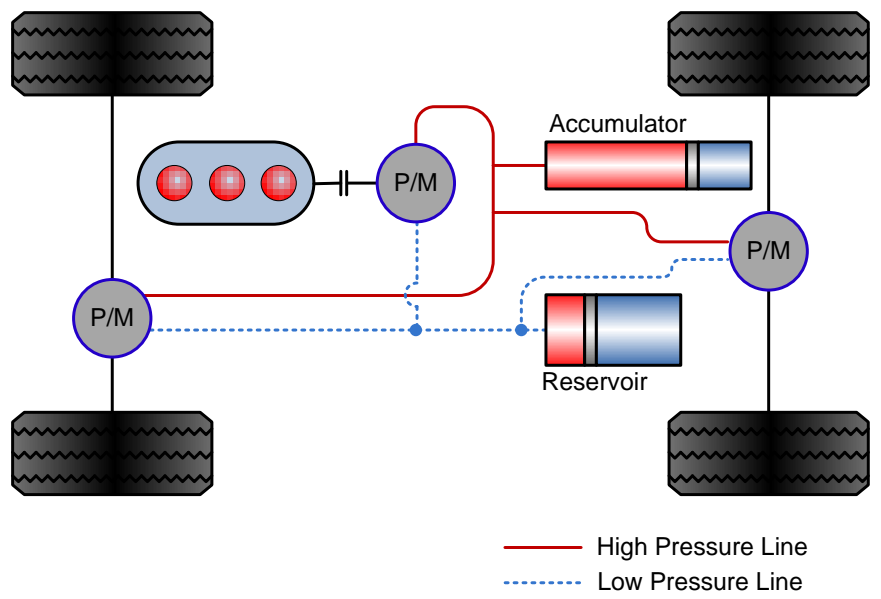

Figure 8 : Series Hydraulic Hybrid Architecture

The greatest difference between the hydraulic and electrical system pertains to energy storage. In contrast to the battery, the hydraulic accumulator is capable of accepting high rate of charging or discharging, but its energy storage capacity is lower. The former is a significant advantage in a series system, while the latter creates a unique controls challenge. As stated in the introduction, it is our objective to maximize the benefits through application of advanced controller design methodologies including the horizon-optimization.

Table 3 gives the specifications of the series hydraulic hybrid vehicle proposed in this work. The engine for series hydraulic hybrid vehicle is basically the same as Honda Insight stock engine, and its SIMULINK model has been described in an earlier section of this paper. The vehicle specifications are the same as for the IMA HEV baseline except the vehicle mass. In case of the series HHV, the complete mechanical driveline and electrical sub-system with the battery are removed and replaced with compact hydraulic pump/motors and the accumulators. Assuming the advanced bladder accumulator design with the carbon-fiber shell, and relying on documented hydraulic pump/motor specific power [1], we estimate vehicle mass reduction shown in Table 3 (723 kg for SHHV compared to the $962 \mathrm{~kg}$ baseline). Most of the results in this paper are obtained assuming the $723 \mathrm{~kg}$ vehicle mass. However, in the very last step we consider the "skeptical" scenario, and repeat the fuel economy calculations for the SHHV using the same mass as in the case of IMA HEV. This provides an indication of how much of the fuel economy improvement can be attributed to the hybrid powertrain only.

Table 3: Series Hydraulic Hybrid Specifications

\begin{tabular}{|c|c|c|}
\hline Engine & $\begin{array}{l}\text { Description } \\
\text { Max. Power } \\
\text { Max. Torque }\end{array}$ & $\begin{array}{l}\text { 1L VTEC } \\
49 \mathrm{~kW} @ 6000 \text { RPM } \\
90 \text { Nm @ } 4600 \text { RPM }\end{array}$ \\
\hline \multirow[t]{3}{*}{ Pump } & Design & $\begin{array}{l}\text { Axial Piston Variable } \\
\text { Displacement }\end{array}$ \\
\hline & Size & $25 \mathrm{cc} / \mathrm{rev}$ \\
\hline & Max Power & $\begin{array}{l}58.3 \text { kW @ } 350 \text { bar } \\
@ 4000 \text { RPM }\end{array}$ \\
\hline \multirow[t]{3}{*}{ Motor } & Design & $\begin{array}{l}\text { Axial Piston Variable } \\
\text { Displacement }\end{array}$ \\
\hline & Size & $20 \times 2 \mathrm{cc} / \mathrm{rev}$ \\
\hline & Max Power & $\begin{array}{l}46.6 \text { kW @ } 350 \text { bar } \\
@ 4000 \text { RPM }\end{array}$ \\
\hline \multirow[t]{3}{*}{ Accumulator } & $\begin{array}{l}\text { Capacity (Max. } \\
\text { Gas Volume) }\end{array}$ & 20 Liter \\
\hline & Max Pressure & 350 bar \\
\hline & Min Pressure & 120 bar \\
\hline \multirow[t]{6}{*}{ Vehicle } & Type & Sedan \\
\hline & Weight & $723 \mathrm{~kg}$ \\
\hline & Coeff. of Drag & 0.25 \\
\hline & Frontal Area & $1.9 \mathrm{~m}^{2}$ \\
\hline & Tire Radius & $0.275 \mathrm{~m}$ \\
\hline & Final Drive Ratio & 3.21 \\
\hline Transmission & $\begin{array}{l}\text { Design } \\
1^{\text {st }} \text { Gear Ratio } \\
2^{\text {nd }} \text { Gear Ratio }\end{array}$ & $\begin{array}{l}2 \text { speed automatic } \\
4: 1 \\
1: 1\end{array}$ \\
\hline
\end{tabular}

\section{HYDRAULIC PUMP/MOTOR}

The hydraulic pump/motor is an axial piston variable displacement type. The P/M model is an updated version of Wilson's pump/motor theory [10]. The torque and flow are controlled by the displacement command to the $\mathrm{P} / \mathrm{M}$. Details of the model are provided in Filipi et al. [2] and Kim et al. [4]. The theoretical flow and torque output are calculated first, and the losses are estimated based on physics-based expressions. The flow losses encompass the laminar, compressibility and turbulent leakage (or "slip"), and the torque losses comprise viscous, hydrodynamic and mechanical. The expressions include constants than need to be calibrated using available experimental data [1], but once that is accomplished the model is capable of capturing effects of all operating parameters. Figures 9 and 10 show trends of pump/motor torque and volumetric efficiencies with 
pressure, displacement and speed, and illustrate an important difference compared to electrical machines, namely an added dimension due to the pressure dependency. The pressure difference across the machine will vary within a wide range during vehicle operation; hence both the absolute level of peak torque and the efficiencies will vary with it. This creates an additional challenge in controller development and requires care in assessing performance constraints.

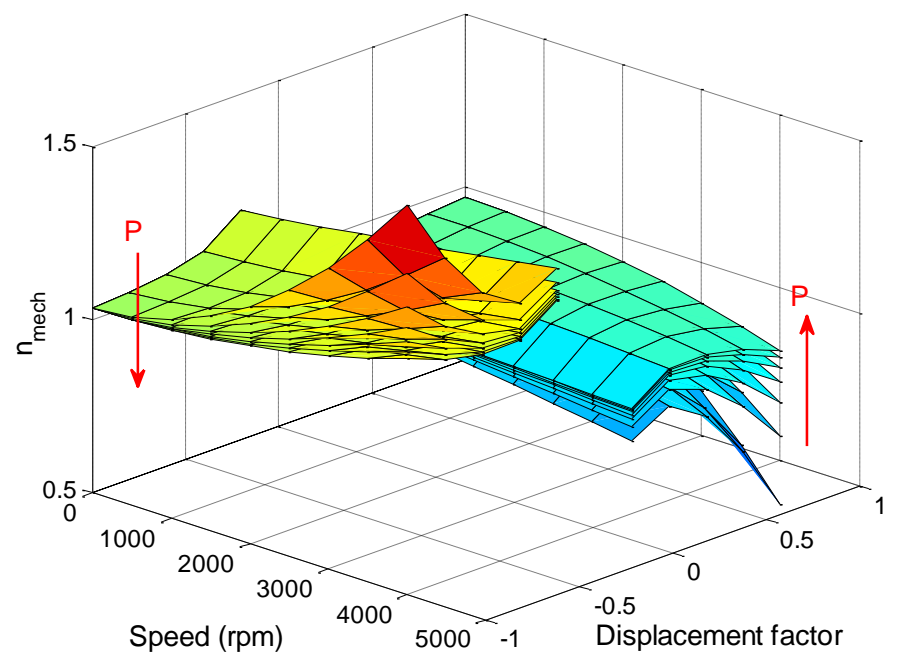

Figure 9 : Pump/Motor mechanical efficiency as a function of "load" (i.e. displacement factor), speed and pressure difference across the machine

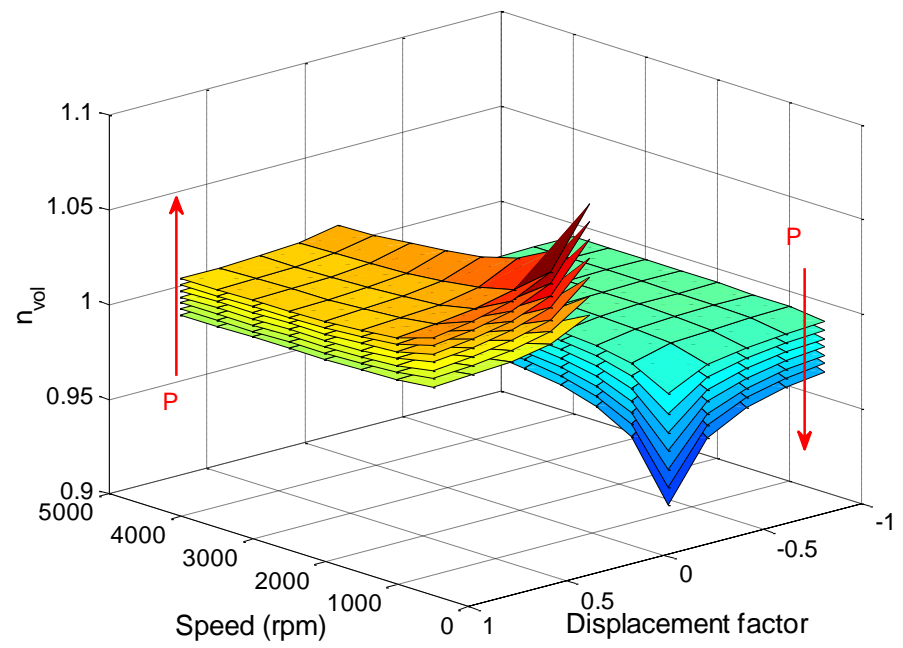

Figure 10 : Pump/Motor volumetric efficiency as a function of "load" (i.e. displacement factor), speed and pressure difference across the machine

\section{ACCUMULATOR}

A hydro-pneumatic accumulator is used for energy storage. A positive fluid flow rate into the accumulator compresses the nitrogen gas stored in the bladder, thus storing energy. A low pressure reservoir is used in the system to prevent cavitation of hydraulic devices. The net head pressure on hydraulic devices is the difference between accumulator and reservoir pressure.
Bladder keeps the gas separate from the oil and hence can be treated as closed system. In order to correctly predict the accumulator dynamic performance and efficiency, a full thermodynamic model is used. It is derived from considerations of energy conservation [2, $10,11]$, and includes the effects of heat transfer and the real gas properties based on the BWR equation.

The thermodynamic analysis clearly shows the significance of the thermal time constant, $\tau$ :

$$
\tau=\frac{m_{g} c_{v}}{h A_{w}}
$$

where $m_{g}$ is the mass of gas, $c_{v}$ is specific heat, $h$ is the heat transfer coefficient and $A_{w}$ is the area of the wall exposed to the gas. The efficiency of chargingdischarging is a strong non-linear function of the thermal time-constant, therefore increasing the heat capacity $\left(m_{g} c_{v}\right)$ and reducing the heat loss $\left(h A_{w}\right)$ is beneficial. This insight led to a now common practice of adding the elastomeric foam to the gas side in order to enhance the thermal capacity and elevate the conversion efficiencies to the mid-nineties.

The SOC for a hydraulic device is defined as the ratio of instantaneous fluid volume to accumulator fluid capacity:

$$
S O C=\frac{V-V_{\min }}{V_{\max }-V_{\min }}
$$

In real application, pressure can be used as indicator of SOC, provided the temperature variations are kept low. This is tied to the accumulator design, e.g. the advanced carbon fiber accumulator with foam can minimize the temperature fluctuations significantly enough to satisfy this assumption. The mass of gas is directly related to the pressure range for a given accumulator size. In this work, the mass of gas was chosen to provide a precharge pressure of $12.5 \mathrm{MPa}$ and a maximum pressure of $35 \mathrm{MPa}$.

The sizes of the hydraulic components were determined through systematic assessment of the performance criteria and study of the sensitivity to the accumulator size. The vehicle performance depends solely on the motor output, hence the performance constraints dominate the sizing process. The main goal was to match the performance of the baseline IMA HEV. A twospeed gearbox was integrated in the propulsion subsystem to guarantee that the motor stays within the safe speed range during high-speed highway driving, and to maximize the average motor efficiency during both city and highway driving. 


\section{SUPERVISORY CONTROLLER}

The supervisory control has a profound impact on hybrid system behavior and its ultimate benefits. Therefore, a number of methodologies have been proposed for development of control strategies, ranging from rulebased [13], to Equivalent Consumption Minimization Strategy [14], fuzzy logic [15, 16], or horizon optimization $[17,18,19,20]$. The nature of the series hybrid system, with the engine decoupled from the wheels, allows significant freedom in designing the supervisory control strategy. This creates a special challenge when it comes to application of advanced algorithms, since the typical power-split problem is replaced with a decision about controlling the SOC. Previous studies of series electric systems basically relied on thermostatic (on-off) engine power management according to the State-of-Charge (SOC) in the battery [21, 22]. In this study we begin by analyzing the Thermostatic control of SOC, before moving on to horizon optimization using Stochastic Dynamic Programming. Details are provided in the next section.

The primary task is maximizing the fuel economy, while ensuring safe operation regardless of the driver demand and vehicle states. The gains with the SHHV are expected from effective regenerative braking and optimization of engine operation. Since the duration of zero-power intervals can be significant, engine shutdowns are a third factor potentially contributing to the fuel savings. However, the latter requires special measures to ensure continuous operation of accessories and safe vehicle operation [23].

Previous work on a series hydraulic hybrid [4] showed the advantage of the two motor design over single motor design for a $4 \mathrm{X} 4$ mid-size truck. It was shown that sequential operation can result in better fuel economy over simultaneous operation. The concept is to use only rear motor for propulsion and hence operate it at higher loads resulting in higher efficiency. Front motor augments the torque in extreme cases. While braking, front motor is used for regeneration. The choice between front and rear motor operation was based on weight transfer during acceleration and braking. All results shown in paper are obtained with sequential operation of motors.

\section{THERMOSTATIC STRATEGY}

The thermostatic strategy is designed around the SOC objective and an engine-centric charging strategy. Driver command is sent directly to propulsion motors and ensures that vehicle follows the desired velocity profile. The SOC is a sole variable used to control engine. The particular challenge in controlling hydraulic hybrid stems from the lower energy density of accumulator. While the battery provides a large energy buffer in the HEV system [19], the accumulator charge undergoes rapid transients and can easily be depleted. In that case the control needs to ensure that the power-generation sub-system directly fulfills the needs of the propulsion system and ensures safe operation. On the other hand, the SOC during normal driving should be kept low in order to ensure enough capacity for storing the energy during the next braking event.

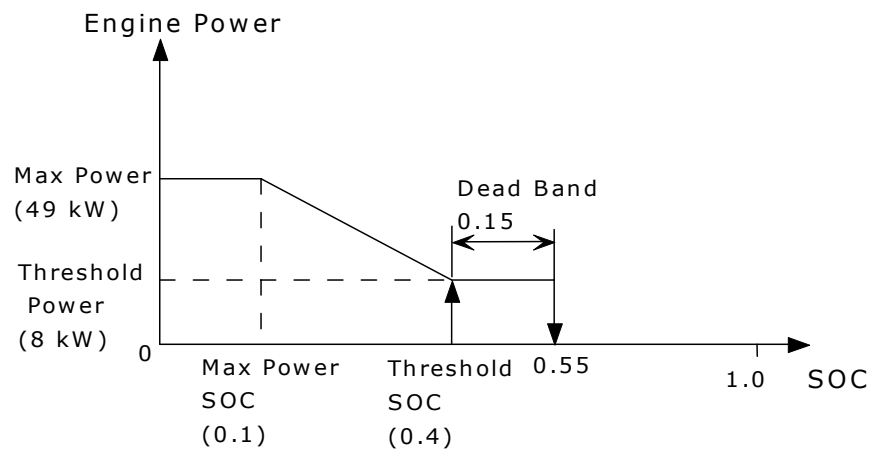

Figure 11 : Thermostatic Power Management

Figure 11 shows the basics of SOC thermostatic control. When SOC is above a threshold value e.g 0.4, the engine power demand is 0 . As the SOC falls below this threshold value, the engine is brought on-line and asked to charge the accumulator. The dead band is implemented to prevent frequent switching between engine on/off states. Therefore, engine continues recharging until SOC crosses the upper limit, i.e. $S O C_{\text {threshold }}+0.15$. In the extreme case of hard acceleration or hill climb, engine is operated at progressively higher power levels as the SOC keeps falling below the threshold. The maximum engine power is requested before the SOC falls below the absolute minimum for a given system.

An integral part of thermostatic controller design is a decision about engine operation during re-charging, i.e. about the threshold power $\left(P_{\text {threshold }}\right)$ and the combination of engine speed/torque for a given power demand. The conventional wisdom suggests keeping the engine at the fuel efficient "sweet spot". The expectation is that running the engine at a most efficient point when charging the accumulator will be the best since the fuel energy conversion comes with smallest relative losses. This neglects the impact of pump efficiency. In addition, this leads to relatively aggressive charging since the "sweet spot" is close to peak torque. Keeping in mind a comparatively small accumulator storage capacity, the resulting system-level effects are short and frequent engine transients [4]. Very rapid engine accelerations consume energy, and engine trajectory passes through sub-optimal regions during dynamic operation. At the same time, short and frequent recharging increases the engine idling time and magnifies the resulting penalty. In summary, the previous experience with a larger vehicle and a diesel engine indicates that the conventional wisdom has to be challenged [4]. Our vehicle is very small, it uses an SI engine, and the dynamic interactions may be very different than in a diesel-powered truck. Therefore, the tradeoffs will be unique and a systematic analysis is required to determine the best $P_{\text {threshold }}$ and $S O C_{\text {threshold }}$ values. 
Engine Operation Strategy in the Context of the Thermostatic Controller

This sub-section addresses the choice of threshold power, threshold SOC and dead band. A series of parametric studies are carried out to find the best combination of these parameters for typical vehicle driving conditions.

Results show that best threshold power from the system point of view does not correspond to the best BSFC point. Instead, Figure 12 indicates that running the engine at much lower power of only $8 \mathrm{~kW}$ leads to best fuel economy. Explanation requires exploring the interactions in the system. Figure 13 shows the engine operation for three different threshold power levels. Charging events become shorter and more frequent with increase in threshold power. Hence, engine spends more time in transients resulting in higher fuel consumption, and short charging leads to extended engine idling in between.

The top line in Figure 12 is calculated for low $S O C_{\text {threshold, }}$ while increased values result in inferior fuel economy. Keeping the target SOC low allows enough capacity for regeneration and is preferred for this application.

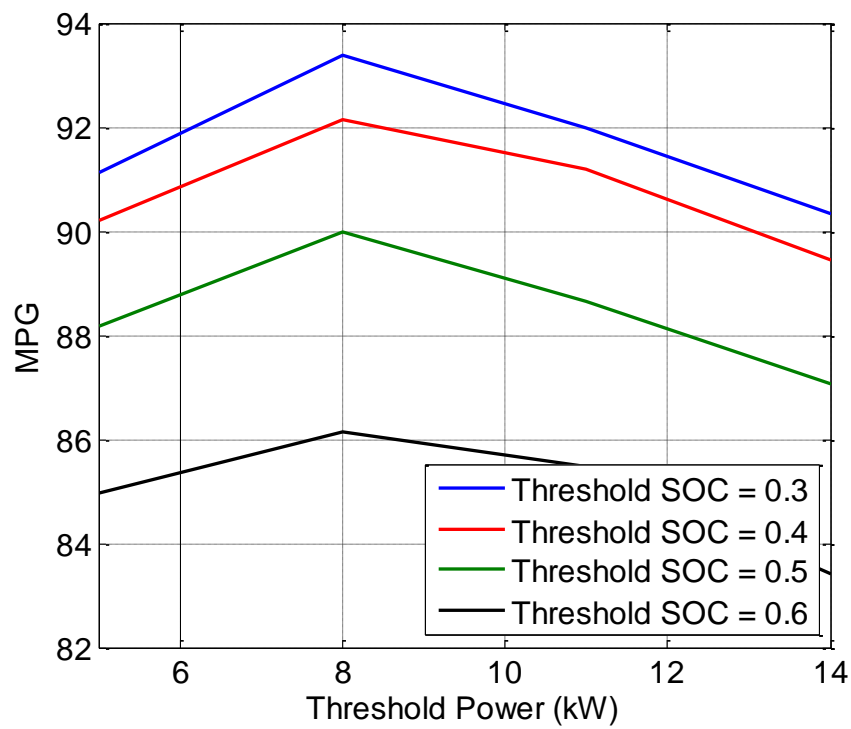

Figure 12 : Results of the parametric study indicating the Threshold Power value leading to maximum fuel economy. Individual lines correspond to different SOC thresholds.

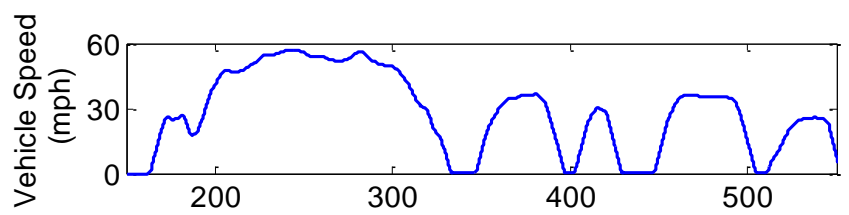

a)

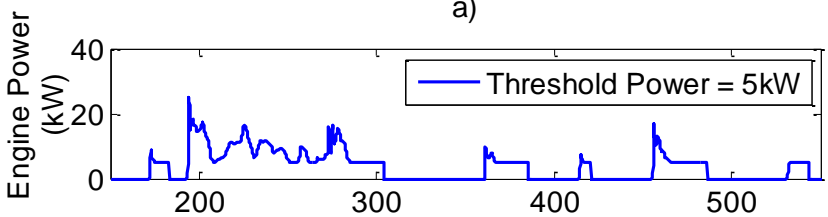

b)

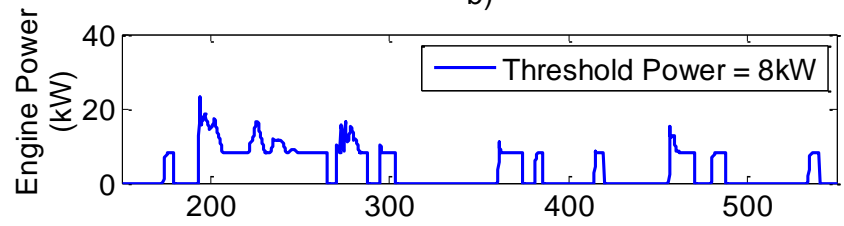

c)

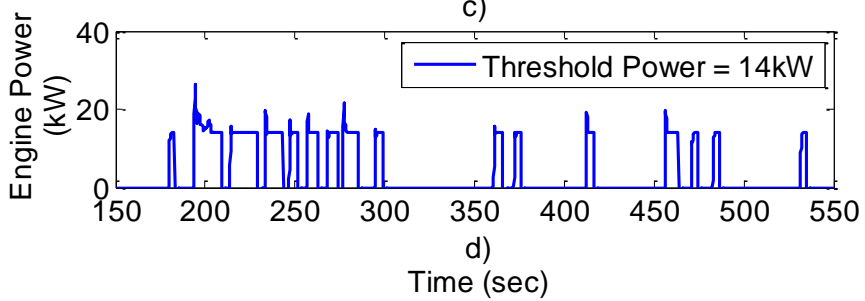

Figure 13: Engine operation in the SHHV with thermostatic SOC control for different threshold power: a) Vehicle Speed, b) Engine Power for $P_{\text {threshold }}=5 \mathrm{~kW}, \mathrm{c}$ ) Engine Power for $P_{\text {threshold }}=8 \mathrm{~kW}$, and d) Engine Power for $P_{\text {threshold }}=14 \mathrm{~kW}$, over section of FUDS cycle (150 to $560 \mathrm{sec}$ ). $\mathrm{SOC}_{\text {threshold }}=0.3$ in all cases.

Results: Series Hydraulic Hybrid with Thermostatic SOC $\underline{\text { Control }}$

The proposed series hydraulic hybrid is simulated over both EPA urban and highway driving schedules. Figure 14 shows the engine visitation points for FUDS cycle and indicates success in operating the engine along the best BSFC line. While the most frequently visited region is not the true "sweet spot", it is still in the zone of very low BSFC. Obviously, the loss of engine BSFC is relatively small and thus far outweighed by the system-level benefits. The vehicle fuel economy over the FUDS is more than $93 \mathrm{mpg}$ with engine idling and $113 \mathrm{mpg}$ with engine shut-downs, Table 4 . While this is certainly impressive, even the most careful parametric studies do not guarantee the optimum. The system-level effects are too complex for intuitive reasoning, hence the motivation for investigating the horizon-based algorithm presented in the next section. 


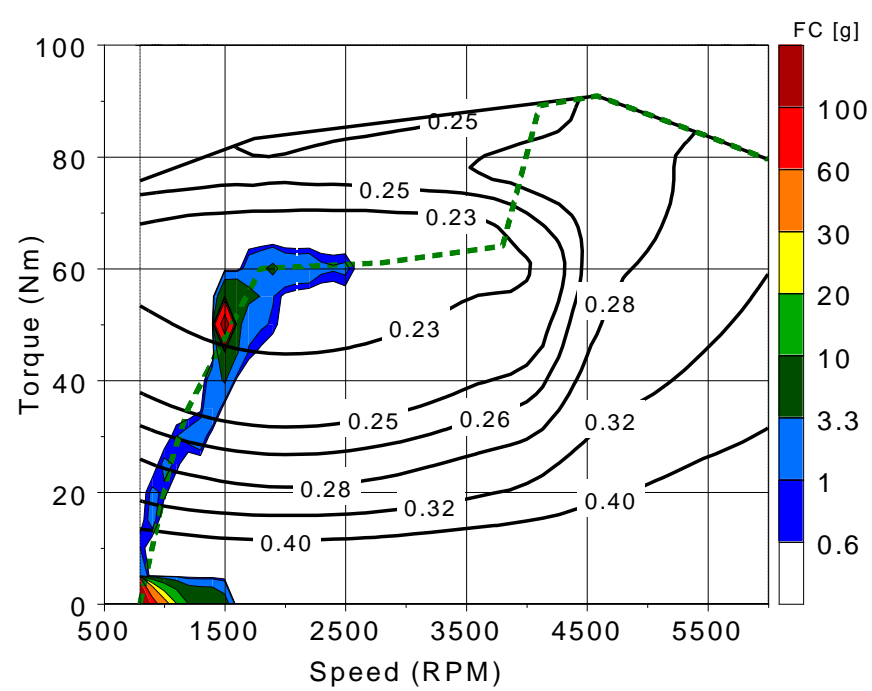

Figure 14 : Engine visitation points on the BSFC map, with a color scale indicating the relative amount of fuel consumed in a given zone during FUDS for Thermostatic controller in SHHV

\section{STOCHASTIC DYNAMIC PROGRAMMING}

Previously published work has shown that application of deterministic dynamic programming (DDP) for controller design enables significant improvements beyond what can be achieved with simple intuitive rules [3, 17, 19, 24]. However, the optimal benchmark obtained by the DDP process is not implementable and subsequent rule extraction sacrifices some of the fuel economy potential [2]. The Stochastic Dynamic Programming (SDP) eliminates the rule extractions step and allows direct development of an implementable control strategy for vehicle supervisory control. SDP is not based on a particular driving cycle (time signal), but rather the statistical characteristics of many driving cycles and hence it is non-cycle-beating. It was previously applied to a parallel hybrid electric vehicle by Lin et al [28] and Liu et al [30], and a first attempt at addressing the series configuration was pursued recently by Kim [29]. The essential part of the supervisory policy in any hybrid is a decision about splitting the vehicle power demand between the engine and the alternative power source. A "soft" connection between the power-generation subsystem and a propulsion subsystem in a series hybrid presents a fundamentally new challenge in applying the SDP concept. Therefore, we split the decision about the threshold power into two decisions, about the engine speed and torque, with the hope that the algorithm may uncover a possible hidden "reserve". In addition, we replace the standard driving cycles for emissions certification with naturalistic driving patterns in an attempt to bring realistic conditions into the controller design process.

\section{Stochastic Modeling of Driver Demand}

Driver power demand is modeled as a discrete-time stochastic dynamic process, and a stationary Markov chain is used to generate the power demand from driver, $P_{\text {dem. }}$. Driver power demand and wheel speed is discretized into finite values

$$
\begin{aligned}
& P_{d e m} \in\left\{P_{d e m}^{1}, P_{d e m}^{2}, \ldots, P_{d e m}^{N_{p}}\right\} \\
& \omega_{w h}=\left\{\omega_{w h}^{1}, \omega_{w h}^{2}, \ldots, \omega_{w h}^{N_{\omega}}\right\}
\end{aligned}
$$

The dynamics of driver power demand is assumed to be

$$
P_{d e m, k+1}=w_{k}
$$

where the probability distribution of $w_{k}$ is assumed to be

$$
\begin{aligned}
& p_{i j, l}=\operatorname{Pr}\left\{w=P_{d e m}^{j} \mid P_{d e m}=P_{d e m}^{i}, \omega_{w h}=\omega_{w h}^{l}\right\} \\
& i, j=1,2, \ldots, N_{p} \quad l=1,2, \ldots, N_{\omega}
\end{aligned}
$$

where $\mathrm{p}_{\mathrm{il}, \mathrm{j}}$ represent the one-step transition probability.
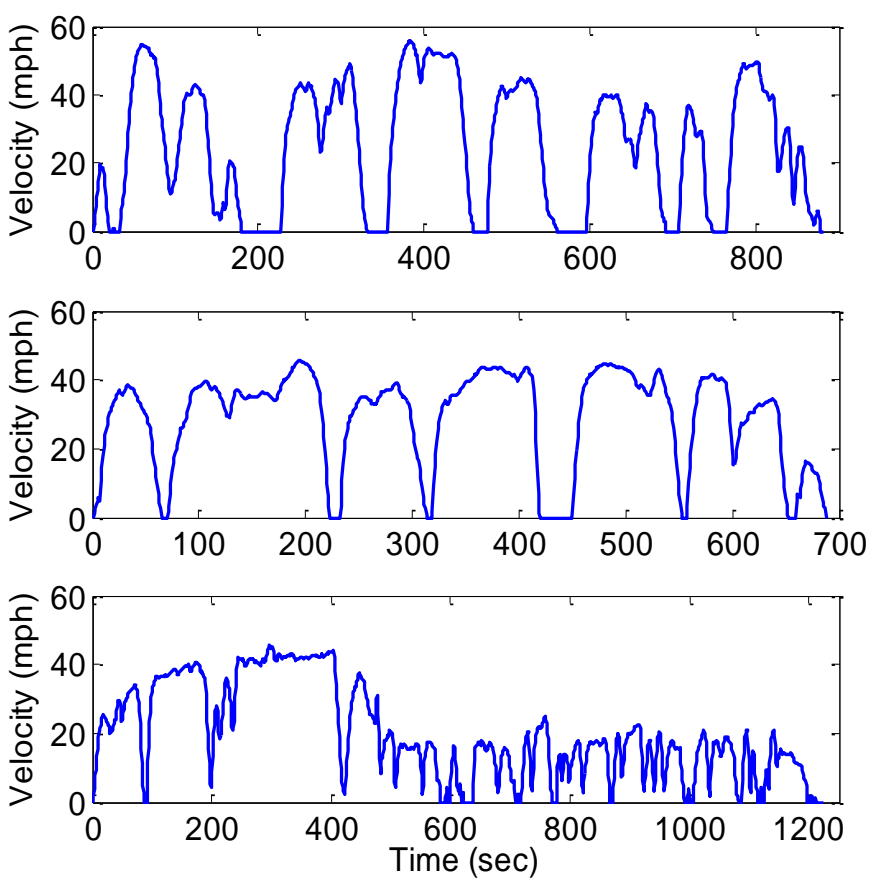

Figure 15 : Naturalistic Driving Cycles recorded during typical commutes in SE Michigan.

The transition probabilities are estimated using the information extracted from naturalistic driving cycles, [12] based on actual behavior of randomly selected drivers in South East Michigan. Figure 15 shows some of the driving cycles used for generating transition probability matrix given in Figure 16. 


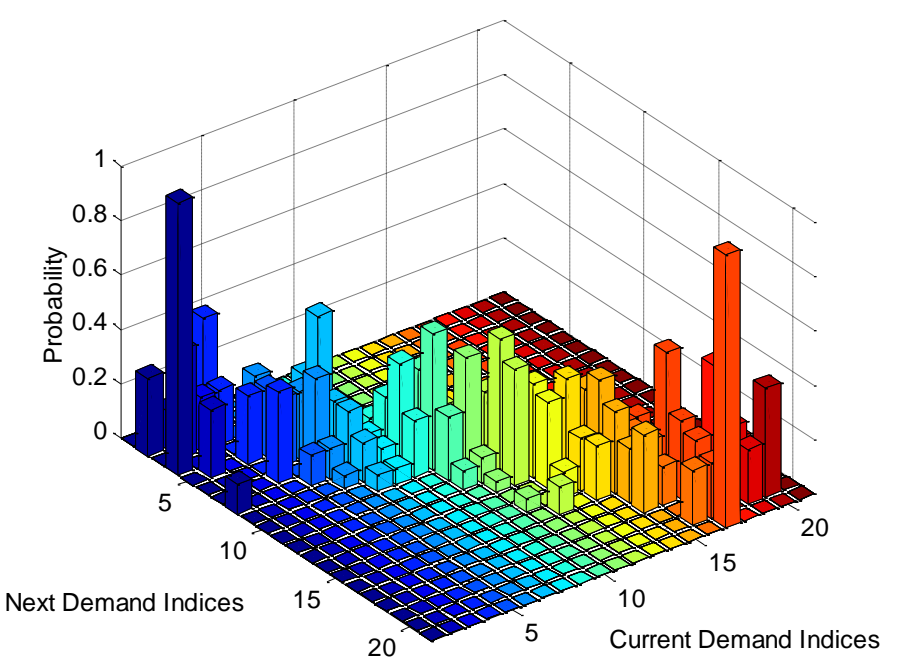

Figure 16 : Transition Probability of power demand $\left(\omega_{\text {wh }}\right.$ $=54 \mathrm{rad} / \mathrm{s}$ ) derived from naturalistic driving schedules.

\section{Problem Formulation}

The objective of the SDP control algorithm is to find the optimal control policy $\pi$ that maps observed states $x_{k}$, (consists of accumulator SOC and vehicle speed $\omega_{w h}$ ) and disturbance, $w_{k}$ (the instantaneous power demand, $\left.P_{\text {dem }}\right)$ to the control decisions $T_{e}$, the engine torque demand and $\omega_{e}$, the engine speed demand. The control policy $\pi$ is to minimize the expected total cost $J_{\pi}$, (fuel consumption) over an infinite horizon.

$$
J_{\pi}\left(x_{0}\right)=\lim _{N \rightarrow \infty} E\left\{\sum_{k}\left\{\sum_{k=0}^{N-1} \gamma^{\kappa} g\left(x_{k}, \pi\left(x_{k}\right), w_{k}\right)\right\}\right.
$$

where $g$ is the instantaneous cost incurred, $0<y<1$ is the discount factor, and $J_{\pi}\left(x_{0}\right)$ indicates the resulting expected cost when the system starts at state $x_{0}$ and follows the policy $\pi$ thereafter. Discount factor implies that the future costs are less important than the same cost incurred at the present time.

The instantaneous cost is based on total vehicle system efficiency and the optimal engine operation is a function of SOC.

$$
\begin{aligned}
& g=F C\left(\omega_{e}, \alpha, S O C\right)+ \\
& \quad \mu \cdot\left(S O C-S O C_{r e f}\right)^{2} \cdot\left(S O C<S O C_{r e f}\right)
\end{aligned}
$$

where $\mathrm{FC}$ is the fuel consumption of engine for an engine speed, $\omega_{e}$, engine command, $\alpha$ and SOC. The latter term penalizes SOC deviation below a reference $\mathrm{SOC}, \mathrm{SOC}_{\text {ref. }}$ This penalty factor is different from the one used by Lin et al [28] for HEV. In HEV, a penalty factor was added to cost function to satisfy charge sustaining constraint and limit the operation of SOC within a narrow window due to battery health and operating characteristics. Hydraulic accumulator does not suffer from similar constraints and SOC can vary over complete range. However, a lower bound on SOC is imposed to maintain vehicle drivable at all conditions. The above penalty function tries to maintain low SOC reference value, e.g. 0.2 in this study, to allow maximum energy regeneration during braking.

The optimization is constrained by the following limits along with deterministic dynamic equations for vehicle, engine and hydraulic devices.

$$
\begin{aligned}
& \omega_{e, \min } \leq \omega_{e, k} \leq \omega_{e, \max } \\
& T_{e, \min }\left(\omega_{e, k}\right) \leq T_{e, k}\left(\omega_{e, k}\right) \leq T_{e, k}\left(\omega_{e, k}\right) \\
& T_{m, \min }\left(\omega_{m, k}, S O C_{k}\right) \leq T_{m, k} \leq T_{m, \max }\left(\omega_{m, k}, S O C_{k}\right) \\
& T_{p, \min }\left(\omega_{p, k}, S O C_{k}\right) \leq T_{p, k} \leq T_{p, \max }\left(\omega_{p, k}, S O C_{k}\right) \\
& S O C_{\min } \leq S O C_{k} \leq S O C_{\max } \\
& \omega_{w h, k}=\omega_{w h, r e q}
\end{aligned}
$$

\section{Approach}

Stochastic dynamic programming problems have been extensively studied in the literature for other applications $[25,26]$. It has been shown that the algorithm can handle constrained nonlinear optimization problems under uncertainties. Value iteration is the principle method for calculating optimal cost-to-go vector. However, value iteration requires infinite iterations to obtain optimal policy. In this study, an approximate policy iteration algorithm is used as it is guaranteed to terminate finitely.

The policy iteration algorithm iterates between a policy evaluation step and a policy improvement step until the optimal cost function converges. In the policy evaluation step, given a proper policy $\pi$, the corresponding cost function $J_{\pi}(x)$ is calculated by iteratively updating the Bellman equation

$$
J_{\pi}^{s+1}\left(x^{i}\right)=g\left(x^{i}, \pi\left(x^{i}\right), w^{i}\right)+\underset{w}{E}\left\{\gamma J_{\pi}^{s}\left(x^{\prime}\right)\right\}
$$

for all $i$, where $s$ is the iteration number, and $x^{\prime}$ is the new state, i.e., $x^{\prime}=f\left(x^{i}, \pi\left(x^{i}\right), w\right)$. In the policy improvement step, the improved policy is found through the following equation

$$
\pi^{\prime}\left(x^{i}\right)=\underset{u \in U\left(x^{i}\right)}{\arg \min }\left[g\left(x^{i}, u, w^{i}\right)+\underset{w}{E}\left\{\gamma J_{\pi}\left(x^{i}\right)\right\}\right]
$$

for all $i$, where $J_{\pi}$ is the approximate cost function obtained from the policy evaluation step. A new proper policy, $\pi^{\prime}$ is calculated and the policy evaluation step is repeated with new policy to update the cost function. This iterative process is repeated, until $J_{\pi}$ converges within a selected tolerance level. The resulting control policy, $J_{\pi}$ is stationary i.e. optimal rule does not change from one stage (time) to the next and can be implemented in controller as a lookup table. 
Previous work on SDP based supervisory controller for hybrids treated engine power demand as the control decision. The engine was then asked to provide the power by operating in the best BSFC region. In this study, engine is not restricted to operate along the best BSFC line, since the insight from the thermostatic SOC study clearly indicates that system-level gains may offset a small loss of BSFC. The intention is to provide an additional degree of freedom and allow the algorithm to discover the best way to run the power-generation subsystem. Hence, the controller produces desired set point for both engine speed and torque, based on given states of the vehicle, driver power demand, SOC and vehicle speed. The results are captured in state-feedback lookup tables shown in Figures 17 and 18. The set points guarantee optimal operation of the whole system, namely engine and pump, rather than just engine. This is a key distinction between this work and the previous attempt [29].

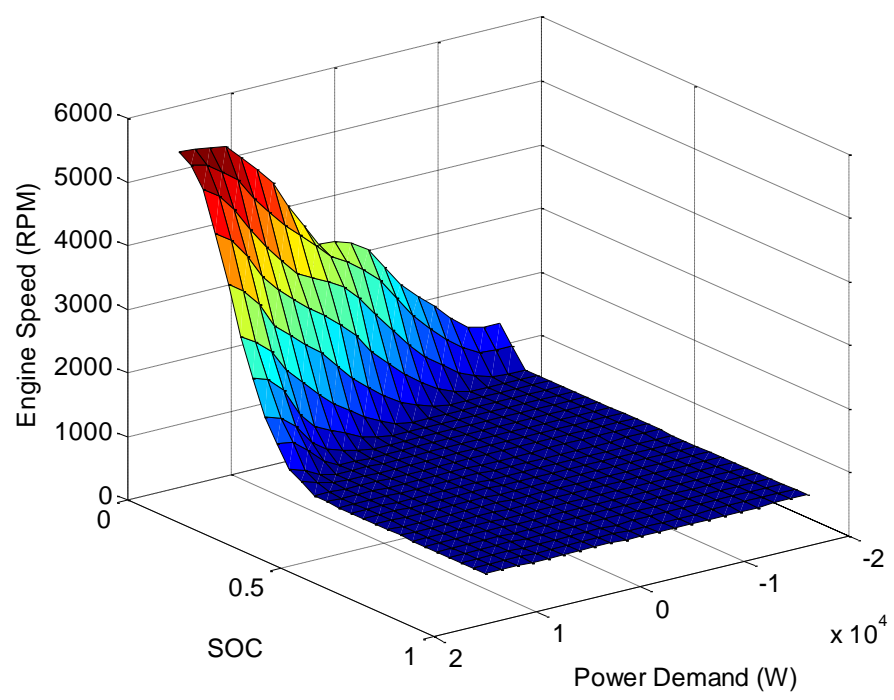

Figure 17 : Optimal SDP Engine Speed policy $\left(\omega_{\mathrm{wh}}=54(\mathrm{rad} / \mathrm{s})\right)$

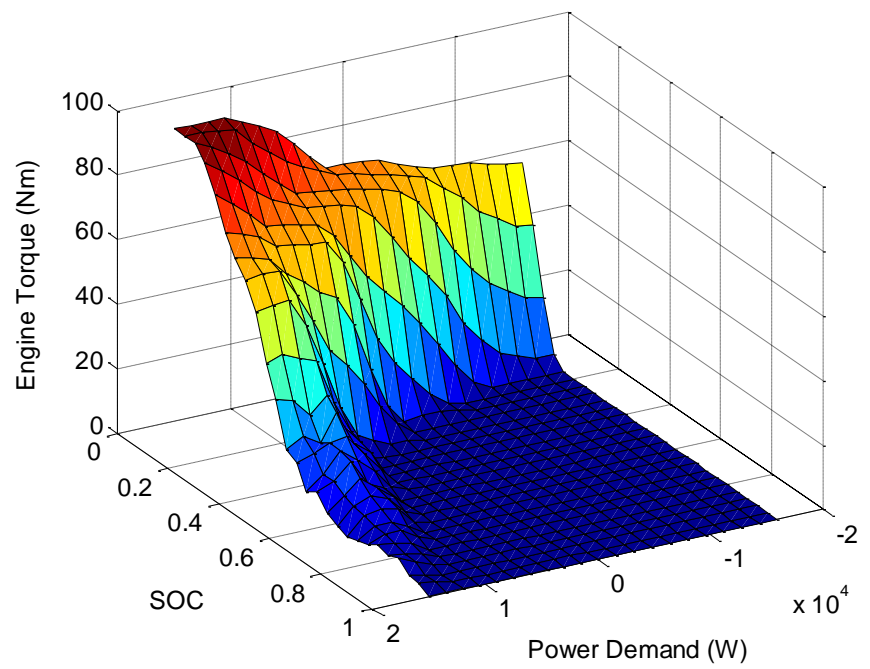

Figure 18 : Optimal SDP Engine Torque policy $\left(\omega_{\mathrm{wh}}=54 \mathrm{rad} / \mathrm{s}\right)$ $\underline{\text { Results - Series Hydraulic Hybrid with SDP controller }}$

Figure 19 and Figure 20 show the engine operation over FUDS driving cycle. It can be seen that engine operation departs significantly from the best BSFC line. The SDP policy operates the engine to maximize the system efficiency rather than just engine operation (Figure 14). Pump efficiency is higher for lower speeds and high displacement command (see Figure 9), and hence optimal set points from SDP controller are shifted towards low speed and high torque region, Figure 19.

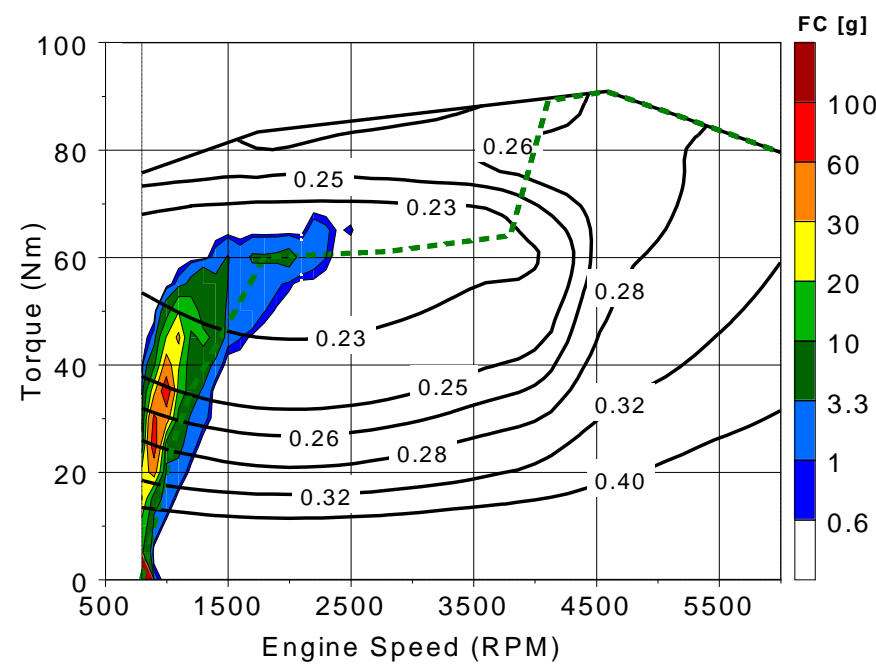

Figure 19 : Engine visitation points on the BSFC map, with a color scale indicating the relative amount of fuel consumed in a given zone during FUDS for SDP based controller in $\mathrm{SHH}$

It can be seen from Figure 20 that SDP based controller does a good job in maintaining low SOC throughout the driving cycle. The controller uses hydraulic power for vehicle propulsion at high SOC values (engine demand is zero, Figure 20). As SOC drops, engine is ramped up and produces enough power to maintain the desired value, 0.2 in this case. This allows maximum regeneration capability during braking events. The engine operation resembles load-following mode, except the speeds are much lower than in the case of a mechanical transmission, hence pushing the loads up into the high-efficiency region.

Table 4 shows the fuel economy of series hydraulic hybrid over EPA standard cycles for the urban and highway federal driving schedule along with percent improvement over the baseline IMA HE vehicle. It includes predictions obtained with both supervisory control strategies, i.e. the thermostatic and the SDP. The fuel economy of the SHHV under city driving conditions is much better than the baseline IMA HEV with either control strategy. The improvements range from $52 \%$ to $85 \%$ without and with engine shutdowns, respectively. The advantage of the SHHV over the highway cycle is smaller, but still tangible. The mechanisms of improvement are explained in the subsequent section. 

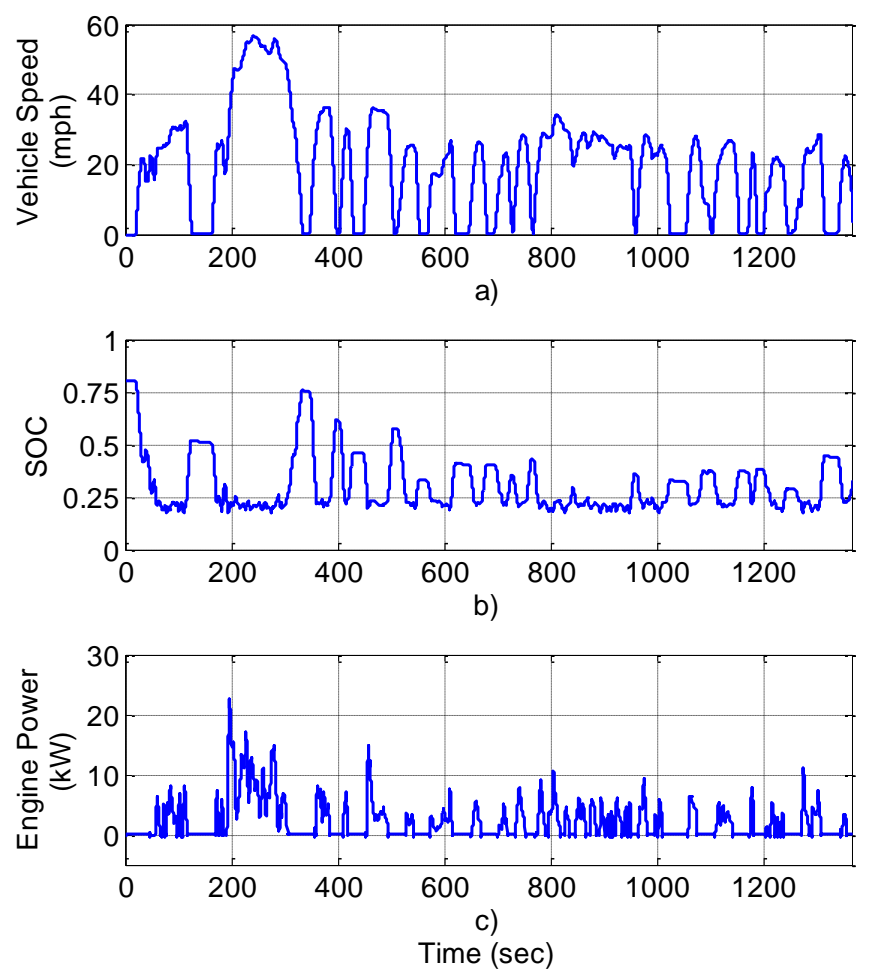

Figure 20 : SHHV results with SDP controller during a section of FUDS schedule.

The SHHV fuel economy predictions without engine shutdowns are virtually the same for the Thermostatic and SDP control. Apparently there was simply not much room for improvement with optimized tradeoffs, and the SDP results confirm the fuel economy potential of the SHH system applied to a small car. However, the SDP strategy differs from the Thermostatic in a very important way that would give it an edge in a practical application. The engine operation is closer to load-following, but with higher load \& lower speed operation than in the case of the vehicle with mechanical transmission. In other words, the transients are relatively mild, but related to vehicle performance. This would result in a much better driver feel than occasional bursts of power experienced with the thermostatic controller. In addition, the likelihood of demonstrating the same results with real hardware is higher in case of the SDP than thermostatic control. Previous work on engine-in-the-loop testing by Filipi et al [27] has shown excellent agreement between predictions and experiments in case of milder engine operation, and tangible discrepancies in case of the bang-bang control. The penalties associated with rapid transients (energy for acceleration, excursions of operating parameters) are obviously not fully captured with a system-level simulation. Consequently, the comparison between thermostatic and SDP would likely swing in favor of SDP in practical implementations. This, together with the drivability considerations and easier management of the aftertreatment system makes the SDP a preferred option. This would also be a very robust controller, since SDP produces directly implementable state-feedback lookup tables.
Table 4 : Series Hydraulic Hybrid Fuel Economy

\begin{tabular}{lccc}
\hline & $\begin{array}{c}\text { Series HHV } \\
\text { Thermostatic } \\
\text { Control } \\
\text { w/o and w/ } \\
\text { engine } \\
\text { shutdown }\end{array}$ & $\begin{array}{c}\text { Series HHV } \\
\text { SDP } \\
\text { Control } \\
\text { w/o and w/ } \\
\text { engine } \\
\text { shutdown }\end{array}$ \\
\hline $\begin{array}{l}\text { Urban } \\
\text { Cycle } \\
\text { (FUDS) }\end{array}$ & Improvement & $52 \% / 84.2 \%$ & $51.8 \% / 74.5 \%$ \\
\hline $\begin{array}{l}\text { Highway } \\
\text { Cycle } \\
\text { (HWFET) }\end{array}$ & Improvement & $85.8 / 87.3$ & $86.4 / 87.3$ \\
\hline
\end{tabular}

As indicated in an earlier section, the SHHV car is lighter than the baseline IMA-HEV. However, by simply changing the simulation input we can make masses of both vehicles equal in order to isolate the effects of hydraulic hybrid propulsion on fuel economy, Table 5.

Table 5 : Series HHV Fuel Economy with Thermostatic controller with engine shutdowns

\begin{tabular}{lccc}
\hline & & $\begin{array}{c}\text { Vehicle Mass } \\
(723 \mathrm{~kg})\end{array}$ & $\begin{array}{c}\text { Vehicle Mass } \\
(962 \mathrm{~kg})\end{array}$ \\
\hline $\begin{array}{l}\text { Urban } \\
\begin{array}{l}\text { Cycle } \\
\text { (FUDS) }\end{array}\end{array}$ & Improvement & 113.03 & 91.3 \\
\hline $\begin{array}{l}\text { Highway } \\
\text { Cycle } \\
\text { (HWFET) }\end{array}$ & MPG & $84.2 \%$ & $48.2 \%$ \\
\hline
\end{tabular}

\section{COMPARISON OF THE INTERACTIONS IN THE SERIES HYDRAULIC HYBRID AND THE BASELINE IMA-HEV}

Figure 21 shows the operation of engine in baseline vehicle and proposed series hydraulic hybrid with SDP controller over same section of FUDS cycle. It can be seen that engine operation in a series hydraulic hybrid is independent of driving schedule and is a function of SOC only. This results in milder transients and better fuel economy. Also intermittent operation of engine allows engine shutdown opportunities for further reduction of fuel consumption.

Baseline IMA vehicle is a mild hybrid and the torque contribution by electric motor is only a fraction of the total driveline torque. This is due to the characteristics of the electric motor and battery circuit. Battery imposes a limit on rate of charge and discharge, whereas accumulator does not suffer from such limitations. Figure 22 shows the torque from the electric motor and the hydraulic motor for a section of the FUDS cycle. Clearly, the series hydraulic hybrid uses the motor more aggressively during braking and hence regenerates more energy. 


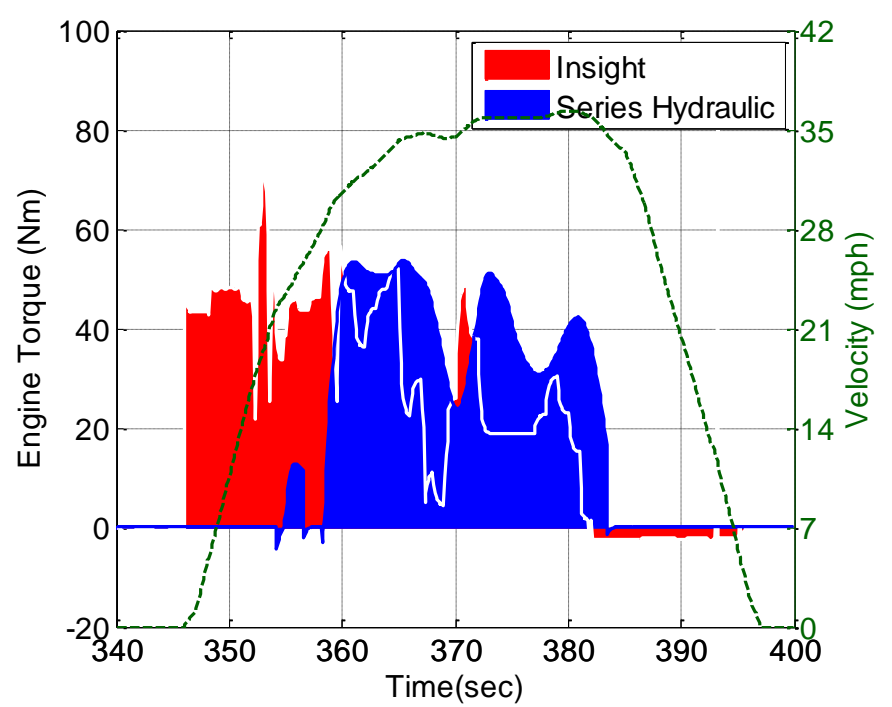

Figure 21 : Engine torque histories for the baseline IMA HEV and the SHHV during a segment of the FUDS.
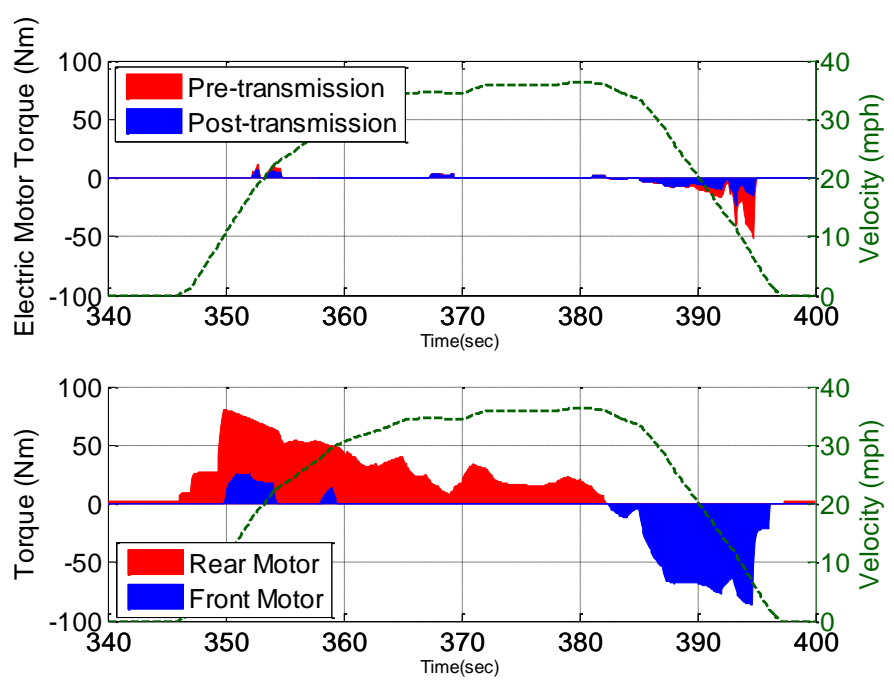

Figure 22 : Torque histories for the electric (top) vs. Hydraulic (bottom) motor operation during a segment of the FUDS.

Fuel economy benefits in series hydraulic hybrid over baseline can be attributed to regeneration, optimized engine operation, and engine shutdowns. Analysis over the city driving schedule attributes $\sim 64 \%$ of fuel savings to regeneration, approximately $34 \%$ to optimized engine operation and the rest to elimination of idling.

\section{CONCLUSION}

A series hydraulic hybrid concept has been explored as a potential technology pathway to an ultra-efficient city car. The target fuel economy was $\sim 100 \mathrm{mpg}$ or $2.4 \mathrm{l} / 100 \mathrm{~km}$ in city driving. Such an ambitious target requires multiple measures, i.e. relatively low mass, favorable aerodynamics and an ultra-efficient powertrain. Hence, the baseline for the study is a first-generation Honda Insight IMA Hybrid Electric Vehicle, as its aluminum structure and aerodynamic body represent the state-of- the-art for a given category. The series hydraulic hybrid powertrain has been designed and analyzed for the selected platform with the expectations that:

- Series configuration will maximize opportunities for regeneration and optimization of engine operation

- Inherently high power density of hydraulic propulsion and storage components will yield small, low-cost components

- High-efficiency of the hydraulic pump/motor and high power limits for accumulator charging/discharging will enable very effective regeneration

Hybrid vehicle system simulation has been developed in SIMULINK for this study. It incorporates physics-based models of energy conversion and storage components allowing full flexibility in considering alternative designs and scaling. The simulation was first configured to represent the Honda Insight HEV system with Integrated Motor Alternator and then validated using published data. Then, the same vehicle platform has been utilized to create a series hydraulic hybrid vehicle, i.e. the mechanical transmission and electric sub-system have been replaced with a hydraulic driveline.

The SHHV study focused on the supervisory control development. This was deemed critical since the low storage capacity of the hydraulic accumulator creates a special challenge for controller development, very different than in the case of electric system. The lowcost objective required keeping the component sizes as small as possible, therefore also emphasizing the impact of power management. Two approaches for supervisory control development were pursued, i.e.:

Thermostatic SOC control, with optimized threshold SOC and power levels, and engine operation on the best BSFC line

Stochastic dynamic programming for horizon optimization of the supervisory policy. The strategy includes selection of engine torque and speed, rather than just the power level. This determines optimum engine operation based on system requirements rather than just BSFC.

The analysis of thermostatic control indicated that operating the engine at very moderate $P_{\text {threshold }}$ during charging leads to much better fuel economy than running at the "sweet spot". Simply, the combination of engine and pump efficiency, as well as the transient events and interactions in the system play a significant role and override the engine-centric policy. Low threshold SOC value is beneficial for regeneration, as it maximizes the storage capacity when needed.

The stochastic dynamic programming was setup using a set of naturalistic driving schedules, recorded in normal traffic. The analysis included additional degree of freedom compared to the traditional approach, as the engine power demand was split into two variables, namely engine torque and speed. The algorithm moved engine torque/speed points away from the best BSFC 
line, in the direction of lower speed and higher load. This is a valuable lesson, indicating what is preferred from the system stand-point. The engine operation resembles load-following mode, except the speeds are much lower than in the case of a mechanical transmission, hence pushing the loads up into the high-efficiency region.

The results of the simulation study of the SHH powertrain indicate that it is possible to attain the target fuel economy with the proposed system and supervisory control. The fuel economy over the US EPA city driving schedule is $93 \mathrm{mpg}$ with either control strategy and engine idling. Allowing the engine to shut-down during vehicle stops elevates the fuel economy to $\sim 110 \mathrm{mpg}$. This represents improvements of $52 \%-84 \%$ over the baseline IMA HEV. The SDP supervisory controller yields smoother engine operation, without sudden and dramatic increases of load seen with the thermostatic control. Since rapid transient come with a price, the SDP results are expected to gain a relative advantage in hardware testing compared to the thermostatic. Therefore, competitive fuel economy, better driver feel and $\mathrm{NVH}$, and easier management of emission control make the SDP controller a preferred option.

\section{ACKNOWLEDGEMENT}

The authors wish to acknowledge Fernando Tavares from University of Michigan for his contributions to hydraulic systems modeling and technical discussions, and Tim Gordon and Zevi Bareket (both UMTRI) for providing naturalistic driving schedules.

\section{REFERENCES}

1. Alson, J., Barba, D., Bryson, J., Doorag, M., Haugen, D., Kargul, J., McDonald, J., Newman, K., Platte, L. and Wolcott, M. (2004) 'Progress Report on Clean and Efficient Automotive Technologies under Development at EPA', EPA420-R-04-002, United States Environmental Protection Agency.

2. Filipi, Z., Louca, L., Daran, B., Lin, C. C., Yildir, U.,Wu, B., Kokkolaras, M., Assanis, D., Peng, H., Papalambros, P., Stein, J., Szkubiel, D. and Chapp, R., "Combined optimization of design and power management of the hydraulic hybrid propulsion system for the $6 \times 6$ medium truck", International Journal of Heavy Vehicle Systems, Vol. 11, No 3-4, 2004, pp. 372- 402.

3. B. Wu, C.-C. Lin, Z. Filipi, H. Peng, D. Assanis, "Optimal Power Management for a Hydraulic Hybrid Delivery Truck", Int. J. Vehicle System Dynamics, 2004, Vol. 42, Nos 1-2, pp. 23-40

4. Kim, Y. J. and Filipi, Z., "Simulation Study of a Series Hydraulic Hybrid Propulsion System for a Light Truck", 2007 SAE Transactions, Journal of Commercial Vehicles, also presented at the 2007 SAE Commercial Vehicle Engineering Congress \& Exhibition, Chicago, October 2007.
5. Achten, P., "Changing the Paradigm", The tenth International Conference on Fluid Power, SICFP'07, Tampere, Finland, 2007

6. Achten, P., "The Hydrid Transmission", SAE paper 2007-01-4152, V116-2007, Warrendale, PA, 2007

7. E. Chiappini and D. Di Rocco, Simulation of HLA Systems in Small Vehicles, EAEC 2007 - 11th European Automotive Congress Automobile for the Future, Budapest, 30 May - 1 June 2007

8. Duoba, M., Ng, H., and Larsen, R., "Characterization and Comparison of Two Hybrid Electric Vehicles (HEVs) - Honda Insight and Toyota Prius", SAE Paper 2001-01-1335.

9. ADVISOR, 2001 Software.

10. Pourmovahed, A., Beachley, N. H. and Fronczak, F. J., "Modeling of a hydraulic energy regeneration system. Part I. Analytical treatment", Journal of ynamic Systems, Measurement and Control, Transactions of the ASME, Vol. 114, No 1, 1992, pp. 155- 159.

11. Otis, D. R. and Pourmovahed, A., "Algorithm for Computing Non Flow Gas Processes in Gas Springs and Hydro pneumatic Accumulators", Journal of Dynamic Systems, Measurement and Control, Transactions ASME, Vol. 107, No.1, 1985, pp. 5359.

12. Adornato B., Patel R., Baraket Z., Gordon T., and Filipi Z., "Characterizing Naturalistic Driving Patterns for Plug-in Hybrid Electric Vehicle Analysis", to be presented at the 5th IEEE Vehicle Power and Propulsion Conference (VPPC'09), Dearborn September 7-11, 2009, Dearborn, MI 48128

13. Bowles, P. D., "Modeling and Energy Management for a Parallel Hybrid Electric Vehicle (PHEV) with Continuously Variable Transmission (CVT)," MS thesis, University of Michigan, Ann Arbor, MI, 1999.

14. Paganelli, G., Guerra, T. M., Delprat, S., Santin, J. J. and Combes, E. "Simulation and assessment of power control strategies for a parallel hybrid car", Proc. Instn Mech. Engrs, Part D: J. Automobile Engineering, 2000, 214(D), 705-717.

15. Farrall, S. D. and Jones, R. P., "Energy management in an automotive electric/heat engine hybrid powertrain using fuzzy decision making." Proceedings of the 1993 International Symposium on Intelligent Control, Chicago, IL, 1993.

16. Baumann, Bernd M.; Washington, G.; Glenn, Bradley C.; Rizzoni, G., "Mechatronic design and control of hybrid electric vehicles," IEEE/ASME Transactions on Mechatronics, v5 no. 1 2000. p 5872, 2000.

17. Lin, C-C., Filipi, Z., Loucas, L., Peng, H., Assanis, D., Stein, J.,"Modeling and Control for a Medium-Duty Hybrid Electric Truck", International Journal of Heavy Vehicle Systems, Vol. 11, Nos. 3/4, 2004, pp. 349370.

18. Lin, C., Filipi, Z., Wang, Y., Louca, L., Peng, H., Assanis, D., Stein, J., "Integrated, Feed-forward Hybrid Electric Vehicle Simulation in SIMULINK and 
its Use for Power Management Studies," SAE Technical Paper 2001-01-1334, 2001.

19. Sciarretta A., Guzzella L., "Control of Hybrid Electric Vehicles - A Survey of Optimal Energy-Management Strategies," 2007, in IEEE Control Systems Magazine, Vol. 27, No. 2, pp. 60-70.

20. Sciarretta A., Guzzella L., Onder C. H., "On the Power Split Control of Parallel Hybrid Vehicles: from Global Optimization towards Real-time Control," 2003, at Automatisierungstechnik, Vol. 5, pp. 195203.

21. Caratozzolo, P. and Serra. M., Riera. J., "Energy management strategies for hybrid electric vehicles", IEMDC'03. IEEE International Electric Machines and Drives Conference (Cat. No.03EX679), Madison, WI, USA, Vol. 1, 1-4 June, 2003, pp. 241-248.

22. Jalil, N., Kheir, N. A. and Salman, M., "A rule-based energy management strategy for a series hybrid vehicle", Proceedings of the 1997 American Control Conference (Cat. No.97CH36041), IEEE, Albuquerque, NM, USA, Vol. 1, 4-6 June, 1997, pp. 689-693.

23. Filipi, Z., Louca, L., Stefanopoulou, A., Pukrushpan, J., Kittirungsi, B., Peng, H., "Fuel Cell APU for Silent Watch and Mild Electrification of a Medium Tactical Truck", SAE Paper 2004-01-1477, 2004 SAE Transactions, Journal of Commercial Vehicles, Volume 113, Section 3, Warrendale, PA, 2004, pp. 1029-1039
24. Liu, J., Peng, H., "Control Optimization for a PowerSplit Hybrid Vehicle", Proceedings of the 2006 American Control Conference, Minneapolis, June 2006, pp. 461-471

25. Bertsekas, D. P., (1995), Dynamic Programming and Optimal Control, Athena Scientific.

26. Puterman M. L., "Markov Decision Processes: Discrete Stochastic Dynamic Programming", New York J. Wiley, 1994.

27. Filipi, Z. and Kim, Y. J.," Hydraulic Hybrid Propulsion for Heavy Vehicles: Combining the Simulation and Engine-in-the-Loop Techniques to Maximize the Fuel Economy and Emission Benefits", Les Rencontres Scientifiques de l'IFP, Advances in Hybrid Powertrains , 2008

28. Lin, C. C., Peng, H., Grizzle, J. W., "A Stochastic Control Strategy for Hybrid electric Vehicle", Proceeding of the 2004 American Control conference, Boston, Massachusetts, Vol.5, 2004, pp. 4710- 4715

29. Kim Y J, "Integrated modeling and hardware-in-theloop study for systematic evaluation of hydraulic hybrid propulsion options", doctorate thesis, University of Michigan, 2008

30. Liu, J., Peng, H., Hagena, J., Filipi, Z.,"Engine-in-theloop study of the stochastic dynamic programming optimal control design for a hybrid electric HMMWV", International Journal of Heavy Vehicle Systems, 2008 